\title{
eLearning Meeting Modular Education, the Case of Learning Objects
}

\section{Lorenzo Cantoni and Luca Botturi}

The topic of modularity is a lively issue in eLearning, both concerning the support that new technologies can offer to the implementation of modular programs and the production of technically and didactically sound learning objects. Several authors have proposed a new object oriented learning paradigm, which builds on the possibility to chunk the learning experience into clearly defined and small units of learning. If the analogy with software programming is interesting and stimulating, it is also necessary to consider the big differences between the two of them. The paper introduces both perspectives - from modularity to eLearning and vice-versa - reporting experiences done at the USI and at the ISPFP and providing a broad discussion about learning objects.

\section{Different Crossroads between eLearning and Modularity}

Modularity can be defined as «a meaningful component of a broader learning path, highly homogeneous, coherent, with a deep conceptual structure» (Domenici, 1989. English translation of the authors). In the eLearning domain, this definition echoes more recent definitions of learning object (LO), i.e. the «smallest meaningful unit of information usable for instruction» (Engineering Education Center [EEC], n.d.). ${ }^{1}$

Of course, the idea of LO refers to a physical - even if digital - object as a learning material, while module refers to a teaching and learning activity. Moreover, while a module has a more or less well defined dimension (some hours of instruction), a learning object seems to have a smaller scale - although the literature does not provide clear indications on the topic. Yet they share several features: both should be meaningful, homogeneous, consistent and structured both define a complex unit that can be used for the construction of more complex learning experiences. As such, both modules and LO should have interfaces that connect them to other components; and both should be described by some 
indicators (metadata) that allow educators and curriculum or course designers to retrieve them and use them for design.

The very intriguing idea of pieces (of learning?) is of the utmost importance in the reflection on eLearning and modularity, two concepts that enhance and support each other, and at the same time rise new issues and challenges.

This article moves in both directions, from modularity to eLearning, and back again, in the attempt to shed some light on the relationship between the two terms, and on the conceptual shared background of education and technologies.

Along the first path - from modularity to eLearning -, we will see how new information and communication technologies (ICTs) can support, enhance and even open wider spaces to modularity in education. Four different implementation strategies will be presented and discussed, exemplified by teaching/learning activities held by the Università della Svizzera italiana (USI, University of Lugano) and by the Istituto Svizzero di Pedagogia della Formazione Professionale (ISPFP, Swiss Institute for the Pedagogy of Vocational Education, Lugano).

The second path - from eLearning to modularity - is devoted to a thorough discussion of learning objects. At first their history and state-of-the-art will be presented, and then we will discuss some advantages and shortcomings of the LO approach to learning technologies, which a modular approach to education might actually share.

\section{From Modularity to eLearning}

Digital ICTs offer a great potential to support modular educational programs, in order to increase the benefits of modular programs and to compensate their drawbacks. In this article, we will explore four main strategies, selected for their fit to the topics of this volume: (a) creating a favourable environment for supporting peer communication in a modular learning environment; (b) enhancing face to face sessions; (c) supporting individual or group distant mentoring and tutoring services; and (d) allowing flexible learning.

\section{Supporting Peer to Peer Communication}

Flexibility can be with full right considered to have a place among the benefits of modular learning environments. Learners-workers can complete large programs and get a degree thanks to the possibility of organizing their time and distributing the learning workload as convenient. This fact has also drawbacks. Modular environments in fact do not foster community building and sharing among the learners - people often meet only when attending face to face sessions and do not establish a durable collaboration relationship. eLearning technologies can support the implementation of a modular educational structure overcoming this limitation. ICT offer an opportunity for creating tools that support peer com- 
munication in "dead periods» between two modules, thus fostering the creation of a learning community that involves learners continuously and generates a supportive environment from which also face to face sessions may benefit.

In order to describe the impact that technologies may have on this issue, imagine that two universities in two different countries create two master programs in Educational Communication that share part of their modules. One of the reasons for this exchange is surely cultural: the program organizers want to foster inter-cultural exchange between the participants, so that they can compare their educational assumptions and practices against each other. This goal clearly demands more interaction than it is usually possible during the courses class hours - usually $4 \mathrm{~h}$ a week, already planned and full with explanations, exercises and discussions. Unfortunately, students live far away, and are in close contact only with the members of the group with which they share their major project, who are all from the same location.

This is exactly the situation of the Master program in Communication, major in Education and Training (MET, 2005), delivered by the USI, which collaborates with the Master in Comunicazione e Formazione of the Università Cattolica del Sacro Cuore (Catholic University of the Sacred Heart, Milan, Italy). Some courses of the MET program are attended also by ISPFP students, as part of their professional training to become certified vacational teachers.

How do technologies help achieving the goal of intercultural exchange for MET students and their Italian colleagues? Three tools are currently being used. 1. First of all, students are asked to fill-in their online «roster», i.e., a short personal description, which indicates who they are, where they come from, what their background is, why they chose to attend the master program in Lugano and Milano respectively, and a picture. On the one hand, this avoided the repetition of personal presentation for each course, which makes information about the colleagues boring; on the other, it allowed to review this online who's who information at any time, allowing them to e.g. read a message in the forum and say «that looks interesting, I didn't know this guy - who is he?» and maybe get in touch for more discussion on the topic. Personal rosters can also include, if the student wants, the personal email, so that students can also have private exchanges.

2. Second, some of the courses include intensive discussion forum communications, in which students are asked to post questions and messages to the instructor and to read and reply to other students' messages. This activity is mandatory and evaluated, and is guided by the course instructor or teaching assistant: it is in fact well known that online discussions are not self-generated and need guidance. In a course at the beginning of the program students were asked to work on a personal "teaching profile», to post the result and discuss it briefly. They were then asked to read the others' profiles - they ended discovering that some people shared their assumptions, and wondering that others seemed to have a completely different approach to education, thus ma- 
king a first step toward the creation of a community: knowing who takes part in it, and what is the definition of a member.

3. Finally, some tools are in place for sharing practices. Part of their works (especially from labs) is published online, so that other students can go, view it and - if necessary - ask the colleagues the rationale behind it, thus fostering exchange.

These tools (e.g. the personal roster, the discussion forums, and the online publication of students' works), demand a minimal technological infrastructure and learner's competence, yet provide a continuous and flexible environment in which the master courses' experience can expand and build on interpersonal relationships.

It is easy to imagine how these tools - along with others - will acquire a new significance in the last part of the master program, when students will be around the world for their internship, and the exchange of practices, insights and ideas will provide a large benefit in terms of professional knowledge. In the same way, in a different context, these tools would provide a social support to people attending the same modules at different times - maybe in small groups.

\section{Enhancing Face to Face Sessions}

As the definition of Domenici quoted above points out, modular education relies on highly concentrated structures, so that each module/activity is paramount with respect to the whole program. While in a streamlined course repetitions can be afforded, in modular education each session has a unique value, and should be made as effective as possible. Even more, this happens when a module has particular features, e.g., an expert who is invited for a single module. In such a scenario, ICT are also a powerful delivery medium that can provide a tool for enhancing face to face sessions.

It is indeed common to provide learners with a syllabus of the module via the program website, or with specific readings or materials to be used before or during the face to face sessions. This provides room for a quicker focusing in class, and allows students to work on questions that make them ready to handle the content presented by the instructor. The benefits of technologies for face to face sessions extend also after the session: the instructor can publish follow-up materials, ask for feedback, or simply put online session slides or summary, so that students can revise it and be prepared to the next step.

The Master Professionalizzante in Gestione della Formazione (Executive Master in Education Management: MAGF, 2005), organized by the Istituto Comunicazione e Formazione (ICeF, Institute of Communication and Education) at the USI in collaboration with the ISPFP exploits new technologies exactly for this purpose. This program is targeted mainly to school managers, and provides theoretical and practical elements for improving the guidance and leadership in educational institutions. A simple password-protected website collects the digi- 
tal materials of each module, allowing instructors to post their materials after classes, and to provide in advance materials for future sessions. In this way, learners can prepare sessions and be therefore more receptive and interactive, those who cannot attend classes can get the materials all the same; and the website remains as "historical memory» of the learning path the participants have gone through, creating a sort of visible red-thread that connects the modules.

\section{Supporting Tutoring}

Modular programs often acquire seamlessness and coherence from a practical activity that goes along the modules, such as a project work. Tutoring is fundamental in this activity, as it can provide individualized support for transferring what is learnt in the modules in the project activity, overcoming or adapting preexisting practices and fine-tuning methods and procedures to the specific project context. This is even more important when the project work is a relevant part of the program's evaluation, as it is often the case.

In general, tutoring activities can work on three levels:

1. Technical tutoring offers advice and troubleshooting for technical matters, e.g., access to the course website, download of specific materials, etc.

2. Content-oriented tutoring focuses on the course content, and deals with comprehension questions, critical reflections and discussions, etc.

3. Meta-cognitive tutoring provides support about how to go through the module(s), how to study, how to approach an exercise or an activity, etc. ${ }^{2}$

The three types of tutoring have different features and needs, and therefore require different modalities, although they can be assigned to the same person. Technical tutoring can be trivial with respect to the subject matter, but a problem with the Internet connection in an online course could halt the learning progress of a student - so a quick response at anytime is necessary in most cases. Content-oriented tutoring has often a different urgency, but requires a deep knowledge of the content being taught and of the learning materials - so that a specialist is required, and often a short message can be an insufficient medium. Digital technologies offer useful communication tools for accessing individual tutoring services, thus reinforcing the value of project or applied work parallel to a modular structure.

The course in Comunicazione Verbale (Verbal Communication) at the School of Communication Sciences of the USI uses discussion forums and email, blended with face to face sessions, in order to create an effective tutoring waterfall structure. The tools for this course were developed within the SWISSLING Swiss Virtual Campus project (SWISSLING, 2005). The course is attended by 100 students, divided into four groups of 25, each group being assigned a special analysis task («group project»). The group project is supervised by a tutor - an older student who interacts with the group mainly via the online discussion forum. Her/his task is to (a) keep the discussion focused on the topic; 
(b) provide hints and stimuli when the discussion lingers or when a certain point is overlooked or missed; and (c) involve all group members in the discussion, block "super posters» and create a space for more «shy» students. Tutors meet regularly with the course teaching assistant, who is in charge of monitoring the overall situation in all groups, and provides advice about how to approach a certain topic with a specific group working on a particular group project. She/he is also in charge of providing tutors with advice about specific content issues, or to intervene directly in the discussion when necessary. The groups meet twice with the tutor and the teaching assistant for a thorough discussion of their work questions and issues for these meetings are prepared online. The simple tool of online discussion forum becomes in this way a support for a complex social interaction. Tutors provide mainly meta-cognitive support (discussion guidance, how to approach the different aspects of the group project, etc.) to the group, and then act as a first filter for content-oriented issues (which they pass on to the teaching assistant when needed) and technical issues (for which the eLab provides full support).

A text-based asynchronous solution like the SWISSLING one could be integrated with other tools, like an audio or a videoconference for discussing more complex issues.

\section{Flexible Learning}

The integration of the elements presented above offers learners a good chance to enjoy in a larger measure the already mentioned benefits of flexible learning which are proper of modular learning environments.

A good example of this is the course Progettazione Didattica (Pedagogical Design) in the aforementioned MET program. The course is completely online, and spans over a 14-week's period. It is organized into 11 units and builds on a course design project that students do in groups of three. Each unit is composed by readings and activities (like producing a document, conducting an analysis or a survey, posting to a discussion forum), and is proposed within a specific timeframe. Students are all the same able to complete the unit whenever they want there are only three fixed deadlines, which are submissions of different parts of the project. They have also to take part into some discussion forums, which are open only for a specific period (in fact, the course is asynchronous but temporal; see Cantoni \& Di Blas, 2002).

This solution allows students to advance faster than the proposed calendar when they can, or stop for a moment if they wish. They do not loose the track or fall behind because they are supervised by a tutor, who is always available online via the discussion forums, and they can see what the other groups are doing, so that they feel some «social pressure» with the course work.

These four strategies are just a part of what technologies can offer to a modular organization of teaching and learning activities. Technologies can offer some po- 
tential to create a coherent and continuous learning environment, sewing together the different modules in a consistent design, where different activities create a unique framework, and social relationships provide a relevant support. Within a long-lasting technology-supported network of colleagues, completing modules is much more than collecting vouchers for a final diploma - it is a chance for creating a community of practice, a group of professionals who share ideas, methods, goals, and a common identity (Cantoni \& Piccini, 2004; Wenger, 1998).

Educational institutions and organizations can find in eLearning technologies an ally for implementing an offer responding to the needs of the knowledge society: life long learning as a continuous experience of professional (and personal) growth, which takes place in a living community at work.

\section{From eLearning to Modularity: the Case of Learning Objects}

This article moves along the path connecting eLearning and modularity. Up to now, we have moved in one direction, namely from modularity to eLearning, exploring four different strategies taken from the practice in which ICTs can overcome some limitations of modular instruction or support its benefits.

Our next step consists in taking the complementary perspective, asking: how does eLearning (i.e. the educators and designers who work with ICTs) consider modularity? This will lead us back, following our path in the opposite direction, from eLearning to modularity. As all trips, the way back often reveals unexpected viewpoints and promenades. The most important and currently debated issue related to modularity in the eLearning domain is represented by learning objects. We will present here their definition - strikingly similar to that of module along with some issues related to their implementation and use.

eLearning itself needs standardisation processes, to enable and foster the production and implementation of digital materials. In fact, eLearning related planning, production and implementation activities usually require that many people with very different backgrounds work together: subject matter experts, pedagogical designers, media producers, online tutors etc. (Bates, 1999; Botturi, 2004). Of course it was possible - and still it is - that the same person looks after every activity, but this necessarily ends up in a very inefficient process; actually, subject matter experts are not usually expert in media production, and/or in computer mediated educational communication, so that their efforts in eLearning planning and production are often in danger of remaining just a bricolage: the so-called «lone ranger model», as discussed by (Bates, 1999).

In fact, with eLearning, education and training make a step forward into their industrialisation, moving from being a craftsmanship activity - a master working with some assistants, covering all the processes from concept to material devel- 
opment, from delivery to assessment and evaluation - to a wider division of labour, in which different professionals collaborate to design and implement the eLearning experience. In order to make it possible, that many people collaborate in the same effort, the use of a common language, common procedures and common standards is needed.

Moreover, the production cost of digital teaching/learning materials requires that they can be reused many times (hence the issue of re-usability), allowing for easy implementation in different learning management systems (LMSs) and technological platforms, easy update, customisation, linguistic translation and cultural localisation, as well as for an efficient and effective finding in a global market of the suitable product(s), trough a shared way of describing them and storing them in dedicated repositories.

Just to offer a few examples, let us think of three different scenarios where the need of re-usable (little) self-containing digital teaching/learning objects comes out.

1. First scenario: once a module is built up to help learning a mathematical concept (let's say: the properties of sum), it could be used in a basic course, where sum is taught, or in a Logics course, where the very mathematical fundamentals are dealt with, or in a "bridging course», for people wanting to attend an advanced course, but without some pre-required knowledge.

2. Second scenario: a repository of LOs is available in a company's knowledge base - composed by many items about how to fix a machine's problems - and a course is to be set up, to teach new employees how to manage that single machine. Different items in the repository could be singled out, in order to build the needed learning path. (But would it be the same thing, trying to assemble a course about the Second World War using single historical information items?).

3. Third scenario: eLearning modules on specific issues are to be taught in different universities, allowing for minor or major adaptations (as it is frequently the case with Swiss Virtual Campus courses).

To reach the indicated goals (exemplified in these three scenarios), small objects seem to be more suitable than large ones, due to the fact that they can be more easily produced, described, exchanged and modified. Small scale digital objects to be used in learning experiences are referred to as «learning objects», as we will see in what follows.

This section presents both the recent history of LOs and of the connected debate, along with the main players in the field of standardisation, and goes in more details presenting the issue of LOs' metadata. When needed, it underlines the shortcomings of the very concept of LO, as well as problems in its implementation and adoption. A last part will briefly summarize the concerned issues. 
The idea of Learning object and their Standards 3

The idea of LOs was introduced in education as «elements of a new type of computer-based instruction grounded in the object-oriented paradigm of computer science» (Wiley, 2000b), capitalizing on the idea of modularity at micro-level.

Object-oriented programming is a promising and widely used paradigm of software development in which programmers build their applications by specializing, connecting and coordinating reusable software «objects», which are already available or custom made. Its origins date back into the ' 60 of last century.

Imagine the software application that supports the production of official documents in a large local administration body: different departments may have different applications that collects and elaborate different kinds of data, e.g. tax data, personal information of citizens, traffic regulation control, etc. All of them are stored centrally in a large database, to which all special applications are connected. If a department requires a new application to be developed, the software developers would take and reuse a lot of objects which are already in use for other applications, e.g. the objects that make the applications "talk» to the central database; they would then program from scratch just the parts of the application that are actually tailored to the department's needs.

In software programming, objects have some specific features:

1. each objects has a special «inner» part, which is its special characteristic - e.g. the ability to connect to a database, or to display information to the end user;

2. each object has some interface to other objects, so that the database connection object can "talk» to the information display object in a proper way;

3. they are adaptable (usually through inheritance) for specific needs;

4. this makes them reusable.

Object-oriented programming is a software development paradigm that allows a sound scalability and has proved to be economic (Dahl \& Nygaard, 1966). These characteristics became appealing to a number of vendors and commercial actors in the eLearning field during the ' $90 \mathrm{~s}$, which formed consortia in order to promote the introduction of LOs into online education - both as a set of standards for digital learning materials production and as a mental design construct. We will see that the two dimensions have to be dealt with separately.

Like in software programming, LOs can be seen as LEGO blocks: small consistent pieces that can be used in order to create larger structures, i.e. learning units, courses or even programs. This metaphor has been widely criticized (e.g., Wiley, 2000b), as it introduces in the teaching and learning process some assumptions that, despite being valid in software development, result tricky when not even false in education - we will come back to it after the discussion of some standards for LOs. On the other hand, and this is extremely relevant for the purposes of this article, it is easy to see how the design of modular educational programs can benefit from LOs: specific content and learning materials can be easily reused and organized in different structures tailored to the needs of learners. 


\section{Metadata standards}

In 1996 the Learning Technology Standards Committee (LTSC) of the Institute of Electrical and Electronics Engineers (IEEE) began the development of a document setting a standard definition of what a LO is (LTSC, 2005). At the same time, two consortia of commercial players in the eLearning domain got together with the same purpose: in Europe forming the Alliance of Remote Instructional Authoring and Distribution Networks for Europe (ARIADNE), with the support of the European Community (ARIADNE, 2005); in North America giving birth to the Instructional Management Systems (IMS) Project with funding from Educom (IMS, 2005), and to the ADL Consortium (ADL, 2005). The idea then spread wide, and big vendors, like Cisco (CISCO, 2001) or Apple (ALI, 2000), also developed their own proposals, followed by minor vendors, which adapted the idea to their products.

What is all this fuss about? Commercial vendors thought that the time was mature for the introduction of a larger scale economy in digital learning materials: the Internet and Web formats in fact allowed an almost zero-cost reproduction and delivery of information and content, thus allowing envisioning a real market of learning. There was, according to them, one condition: the products to sell, i.e., digital learning materials called LOs, should be identifiable within large repositories, searchable, and compatible with one another. The missing element was a standard format for making LOs a recognizable and marketable product.

Actually, the development of standards by the aforementioned bodies and organizations was the major drive for the discussion about LOs. The most referenced and most widely used standards are those by IMS (called IMS) and ADL (called SCORM - Sharable Content Object Reference Model). Both of them build on the first definition provided by the LOM - Learning Object Model by the IEEE LTSC (LOM, 2005).

It is paramount to recognize that all standards provide a technical definition of what a LO is, which supports a commercial vision of eLearning, but that little space is devoted to the impact that this construct has in terms of design and on the learning process (Gibbons, Nelson \& Richards, 2000).

The following paragraphs will briefly introduce the technical definition of LOs as emerging from the standards - as we already said, this is a merely technical and commercial definition, while some reflections about its educational and design implications are left to the final part of the article.

\section{The Conceptual Definition of a Learning Object}

The LOM (2005) draft defines a LO as «any entity, digital or non digital, which can be used, reused or referenced during technology-supported learning». The definition is actually very broad, and, as Wiley (2000b) points out, «upon examination [it] fails to exclude any person, place, thing, or idea that has existed in the history of the universe». And in fact, this definition does not seem to con- 
sider any knowledge or method about teaching or education in general, and gave rise to a large pedagogical and philosophical discussion about the very idea of LO: if a simple book, or a lamp can be considered with full right a LO, what is in fact the difference between learning, knowledge, information, etc.? We will tackle this issue further on.

CISCO (2001), on the other hand, proposed a more technically-oriented definition of Reusable Learning Object (RLO): «database-driven objects that can be reused, searched, and modified independent of their delivery media». A RLO is therefore something that a student or an instructor can look for, identify within a large collection, retrieve and use independently or in a structure composed by other RLOs. Even better, a RLO would be an element of a larger system which could observe online learners and propose them "on the fly» learning paths, or units, or programs.

The Technical Definition of Learning Object

In any case and for all standard bodies, a LO is a clearly defined piece of software, composed by two parts:

1. The actual content of the learning material (e.g. the texts, pictures, animations, video clips, exercises, etc.);

2. The metadata, i.e. a description of the LO that makes it searchable, retrievable, and comparable with other LOs.

All standard documents focus on two aspects: (a) the physical structure of a LO; and (b) the information contained into the metadata descriptors.

(a) is a straightforward issue, set by LOM and adopted by all standard bodies. For all standards, a LO is a compressed file (e.g. a CAB, TAR, or ZIP file) which contains the content (i.e. the content files) and the metadata, usually coded in XML into a manifest file. The following figure (Figure 1) sketches the structure of a $\mathrm{LO}$ according to IMS.

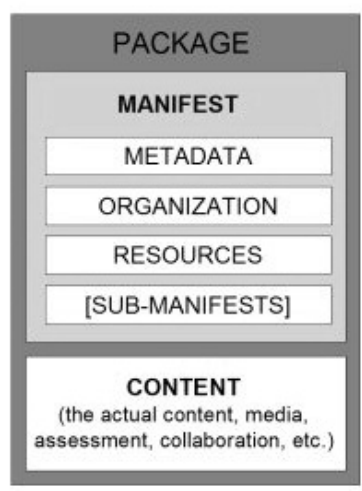

Figure 1: LO Physical Structure (taken from IMS, 2005) 
On the other hand, (b) represents some issues. All standards take their main structure from the LOM draft, and refine it to propose variants. The goal of metadata is to enable the effective storage, search and retrieval of LOs, either by humans or by machines, e.g. by an adaptive LMS. In order to achieve this goal, standards propose a set of descriptors. It is beyond our scope to compare the different solutions, but it is useful to briefly present the IMS solution in order to see some issues at stake.

According to LOM, the main elements of a metadata description should be:

1. identification, i.e., a unique reference for addressing the $\mathrm{LO}$ within a catalogue;

2. language, i.e., the natural language in which the $\mathrm{LO}$ content is presented;

3. ownership, i.e., the authors and the copyright holders, along with the conditions for purchase or reuse;

4. coverage, i.e., the topics addressed in the LO;

5. educational, i.e., information about possible instructional uses of the object;

6. technical information, i.e. the technical formats and requirements in order to access the LO;

7. versions, i.e., what version it is (prototype, stable, etc.);

8. annotations, i.e., comments by the people who built or used the LO.

At a first sight, it is clear that the largest part of the information contained in metadata concerns the development lifecycle of the $\mathrm{LO}$ and its physical features (technical information and language), while very little space is devoted to its educational features - which are indeed most interesting and potentially useful for instructors and educators.

What goes then under the educational part of metadata? It contains descriptors like:

1. education level, i.e. what level is addressed (primary school, secondary school, etc.);

2. intended users, i.e., if the object is targeted to learners, tutors, instructors, etc.;

3. resource type, i.e., what kind of LO it is; possible values are explanation, exercise, assessment, etc.;

4. interactivity type, i.e., if the LO is interactive; the proposed scale, far from being satisfactory, is very low, low, average, high, very high;

5. semantic density, i.e., if the text (if any) is «dense» or not; the proposed scale is the same as for interactivity type;

6. difficulty, i.e., if the $\mathrm{LO}$ is difficult or not - same scale as the previous two elements;

7. estimated time, i.e., how much time a user should devote to it in order to cover it.

An examination of the metadata schema for the educational values reveals that the standard proposals lack an educational insight about the teaching and learn- 
ing process (Wiley, 2000b). What does it mean, «high» interactivity? (Schulmeister, 2003) What text is semantically «dense» for a brilliant 7 th grader? What is «very low» difficulty for one student, will it be the same for another one? Can I reuse a LO developed for 5th graders with 7 th graders in another program? These are actually the issues that potential users are facing in implementing a LO system.

Metadata provide in fact a thorough support for the development, management and exchange of digital learning materials - thus providing also opportunities for modular structures -, but do not offer a proper aid to educators wishing to integrate these objects into their practice. (Parrisch, 2004)

To this we should add the cost of producing metadata. Once some digital learning material is ready to use, in order to have a complete and reusable LO, the author(s) should fill in all (mandatory) metadata elements and create the package, as described above. Current standards have around 70 elements in their metadata structures, i.e. a considerable amount of extra production time.

\section{The IMS Perspective: Automatic Learning}

As we have already mentioned, one of the goals of LOs promoters is, as the Project Authorization Request for LOM puts it, "to enable computer agents to automatically and dynamically compose personalized lessons for an individual learner» (LTSC, 2000). An extremely modular program, as the one enabled by a diffuse use of LOs, would actually allow the development of systems that take care of creating personalized programs and learning plans without human intervention (except maybe supervision) using the building blocks that instructors (or vendors) made available: LOs.

The achievement of this goal, if desirable, requires a state of perfection in the development of learning objects, and in the writing of their metadata descriptors, along with a huge set of information concerning the individual learners, their contexts, their goals, abilities, etc. Yet this is the perspective in which some standard bodies, like IMS, work.

IMS has actually produced a whole suite of standard specifications that describe not only LOs, but the whole context in which learning takes place: the learner's profile, the enterprise or organization to which s/he belongs, learning goals, assessments, sequences of LOs, etc. The following table reports the whole IMS suite (taken from IMS, 2005). 
Table 1 - standards in the IMS suite

$\begin{array}{ll}\text { IMS Specification } & \text { Description } \\ \text { Meta-data } & \text { The tagging of any learning content. } \\ \text { Enterprise } & \text { The exchange of Person and Group information. } \\ \text { Learner Information Package } & \begin{array}{l}\text { To exchange a Person's profile or life-long } \\ \text { learning log. }\end{array} \\ \text { Question \& Test } & \begin{array}{l}\text { Used to support computer-based Assessment. } \\ \text { Content Packaging }\end{array} \\ \begin{array}{l}\text { Exchanging content with its associated learning } \\ \text { structures. } \\ \text { Adaptive learning routes through a set of learning } \\ \text { content. }\end{array} \\ \begin{array}{l}\text { Reusable Definition for Competency and } \\ \text { Learning Design }\end{array}\end{array}$

Currently, no LMS exists that can realize such a vision - even more simple tools as support application for creating metadata or for storing and retrieving LOs are still only under development.

Nevertheless, this perspective has collected many critiques (Gibbons, Nelson \& Richards, 2000; Parrish, 2004, Wiley, 2000b), as it de-personalizes learning, making eLearning technology replace human intervention instead of supporting and enhancing it, and making educational systems a maze of modules instead of an occasion for developing a personal and professional identity, thus perverting the potential of new technologies in modular contexts as we tried to depict it in the first part of this article.

As any technological innovation, LOs need to be framed within a cultural and design context (Jonassen \& Churchill, 2004), or their forcedly limited cultural perspective will reduce its potential and make them a problem instead of an opportunity. The concept and experiences of modularity done so far surely represent a powerful resource in this sense, and many experiences coming from the field of eLearning also point to a different direction - this will indeed be the topic of the next paragraph.

\section{Do Standards Come to the Grips with Learning Objects?}

As we already mentioned, the definition of LOs proposed by standard bodies and organizations raised both deep interest and poignant critiques in the eLearning domain. On the one hand, this means that their proposals do not yet meet 
the needs and experiences of teachers, designers and educators, but on the other it reveals that the idea of LO actually answers to a real need of modularity in the design and development of digital learning materials.

It is also clear that a thorough implementation of LO requires a broad interdisciplinary approach - it is interesting from this perspective to see the structure of the LORNET project (LORNET, n.d.), a research project led by the Téleuniversité du Quebec that aims at providing an all-round suite of methods and tools for effective use of LO. This project covers 6 areas: interoperability/metadata, design and aggregation (how to create learning paths from single LO), adaptive objects for personalized learning, knowledge extraction for the development of high quality LO, advanced multimedia and the integration of the previous 5 areas.

The vision of LOs as LEGO blocks is probably the point on which the largest number of words was spent, and in a way that sheds light also on proper features of any modular learning environment. Actually, thinking of education as a structure of LEGO blocks goes against a situated understanding of teaching and learning, in which educational activities should have a meaning and be contextualized in real settings. Moreover, it implies that any block/LO can be put together with any other one, which is not the case in teaching, where sequencing and the organization of the learning activities play an important part in giving meaning to the content. Collecting these and other critiques, Wiley (2000b) proposed an alternative definition comparing LOs to atoms: LOs are the smaller element in a modular educational environment, but their combination and integration into bigger structures depends on their internal structure and on their «sense-making» together, exactly as atoms form molecules and aggregations following precise structural rules.

We believe that this view has another merit, not explicitly mentioned by its author, namely, the assumption that a LO, like an atom, acquires importance only if it is connected to other (different) elements and forms a unitary whole a learning unit, a course, or - more in general - a learning activity which includes not only other objects but the interaction of learners with the objects, among themselves, and with the instructors. This is actually true of all modular structures: the benefit of having connectable and reusable modules becomes real only if an architect or a designer can put them together meaningfully.

In short, LO standards propose a technical and commercial definition of this construct, leaving to future experiences and progresses to include it into a complete set of design concepts and practices (Gibbons, Nelson \& Richards, 2000).

As for now, few real and standard-compliant LOs are around because of the lack of tools that allow using them, like repositories, metadata editors, LMSs that can incorporate LOs. From a technical point of view, the eLearning community is at work for the development of applications that support the production, management, exchange, adaptation and reuse of LOs.

From a pedagogical or educational point of view, LOs are a design construct which has gained a wide consensus despite the critiques, because it answers to a 
real need for modularity, for reusability and economical reasons. Several initiatives are around for the production and exchange of LOs, like MERLOT (2005): they do not use standard definitions or metadata, rather build on the very idea of reusable digital learning materials.

\section{Problems and issues: a brief summary}

As we have seen before, LOs are surrounded by a great debate, which shows that they are at the same time an important and a controversial issue.

On the one hand, standards and common procedures are strongly needed, if eLearning has to survive, to allow for a sound and sustainable use and re-use of digital learning materials, on the other, the mere adoption of the "objects" model, taken from programming languages, does not seem to be enough, yielding more problems than those it helps to solve.

In particular, the main difference between objects in programming languages and in learning, is that in the first case they are to be interpreted by and interfaced with other technical things (computers, operating systems, other objects), while in the second case they are to be used by human beings.

Second, the result of a learning experience cannot just be interpreted as an addition to a repository, rather than as a change in how a person (/community) sees and interprets the world: "learning is persons» (Cantoni, 2003; Curran, 1976; see also Dufeu, 1994). Knowledge is not just a collection of small LEGO blocks, but a living body, growing trough continuing integrating (digesting) new senses, through «making sense» of what is learned. In simple cases - like, for instance, for competencies required by the ECDL: European Computer Driving Licence (ECDL, 2005) - a given knowledge can be just divided into small pieces, but in more complex cases, this division seems more a dissection, where in the end one sees the different parts of the body, but just dead - than a sound teaching/learning activity.

Third, while software objects need only to have suitable input and output interfaces, in order to implement them and interface them with their running environment, in human learning context is of the utmost importance, and can not be reduced to a mere ordering of different self-containing pieces of knowledge. The metaphor of atoms has already been mentioned; we can map this aspects also onto natural languages, where single lexical items (approximately: words) acquire their meaning only when put in a linguistic context - phrases - and in a communicative context: actual utterances. For instance: in "the sky is blue» and in "the pen is blue», the blueness referred to in the two phrases is very different (actually, in the second case, we could use it to mean both the colour of the object-pen, and the colour it writes: "the pen is blue: but in fact it writes in red»). Moreover, we can utter the first sentence to mean: "we do not need to carry our umbrella", or to mean «unfortunately we cannot expect rain for the grass». In human linguistic communication as well as in human learning all the elements - both linguistic an non-linguistic - mould together, to give birth to a new, creative meaning. 
Fourth, quite often teachers/instructors do not want to widely re-use materials produced by others for other contexts, rather just very little pieces, or elements, to be integrated into a new teaching act (Collis \& Strijker, 2003). A novel trend in Instructional Design which could provide support in this sense is the development of conceptual languages and visual notation systems for reusable designs. E2ML (Botturi, 2003), is a language that takes into account the issue of LO integration, trying to provide a tool for a match of material reuse and sound pedagogy.

Fifth and sixth, very few applications exist that make an extensive use of LOs' standardisation, and LOs' meta-tagging is very expensive, and seldom cost-effective.

The problems pointed out above, call for a re-consideration of the LOs' issue, which has to take into account both the fact that eLearning needs them and the complex human learning experience.

\section{Conclusion}

This paper moved from the observation that the definitions of LO and of module come from different traditions, but still have lot to share. It therefore explored the implications of eLearning technologies for modular instruction, and of modularity for eLearning.

In the first part of the paper we pointed out four strategies that exploit ICT in order to enhance the learning quality of modular educational systems by providing connections and a consistent durative environment to learners. In the second part, we focused on the definitions, applications and assumptions of the idea of LO, the most advanced evolution of modularity in the eLearning domain. It is a recent concept in the learning technology domain and in Instructional Design, and it introduces a strong idea of modularity, with all benefits and pitfalls that this means. The idea of LO is currently strongly debated, and future experience and research will tell in what contexts and under what conditions it can increase the quality of educational programs.

eLearning and modularity are strictly intertwined: both support each other and overcome each other's limitations. But at the same time, they bring about a strong - yet often undeclared - idea of teaching and learning, of which educators and designers should be critically aware. 
Notes

1 For the concept of modularity, and many experiences connected with it, see the other articles in this same issue. eLearning is referred to as being "the use of new multimedia technologies and the Internet to improve the quality of learning by facilitating access to resources and services as well as remote exchanges and collaboration» (CEC 2001, p. 2; for a broader discussion of the definition issue, see also Cantoni \& Di Blas, 2002 and Cantoni \& Tardini, forthcoming). The concept and definition of $\mathrm{LO}$ are discussed in detail further in this article.

2 In fact, in 2001-2002 ISPFP offered a modular program toward a diploma in AP-CMC: Assistente di Pratica in Comunicazione Mediata da Computer (Assistant of Practice in Computer Mediated Communication), whose profile is exactly to provide this third kind of assistance (being equipped to provide also the first one, and to promote an effective and efficient tutoring by subject matter experts (second kind of tutoring) through an early diagnosis of learning problems and an adequate «routing» of questions.

3 In this text, no distinction is made among the different levels of standardisation; in fact, proposals concerning LOs range from just research and development concepts to accredited standards. This continuum can be visualised as follows (taken from Masie, 2003, p. 13):

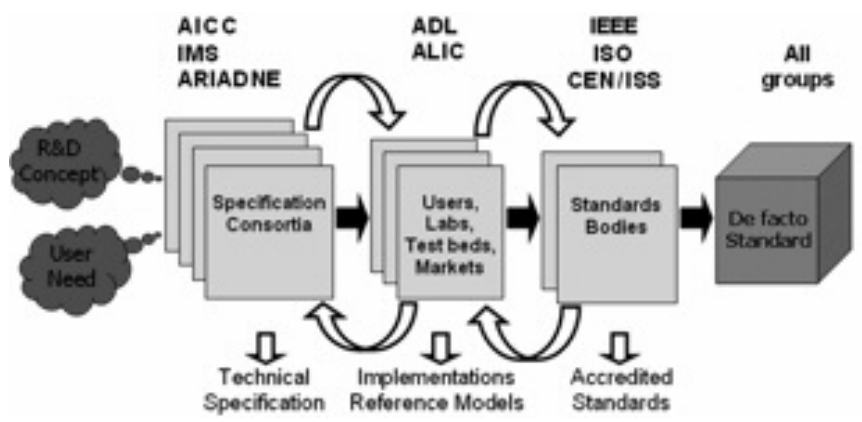

\section{Reference}

All online references were checked January, 2005.

ADL (2005). Advanced Distributed Learning Network. Online [www.adlnet.org].

ALI (2000). Apple Learning Interchange. Online: [http://ali.apple.com].

ARIADNE (2000). Alliance of Remote Instructional Authoring and Distribution Networks for Europe. Online: [http://ariadne.unil.ch].

Bates, T.W. (1999). Managing Technological Change: Strategies for College and University Leaders. San Francisco, CA: Jossey Bass.

Botturi, L. (2004). E2ML A Visual Instructional Design Language. Proceedings of th AECT 2004 Convention - All That Jazz. Chicago, IL. [on CD-Rom]

Botturi, L. (2003). E2ML A Modeling Language for Technology-dependent Educational Environments. proceedings of EDMEDIA 2003. Honolulu, HI: 304-311.

Cantoni, L. (Ed.) (2003). Italian translation of Ch.A. Curran. Il Counseling-Learning nelle lingue seconde, con un saggio introduttivo di Lorenzo Cantoni. Perugia: Guerra Edizioni.

Cantoni, L. \& Di Blas, N. (2002). Teoria e pratiche della comunicazione. Milano: Apogeo.

Cantoni, L. \& Piccini, C. (2004). Il sito del vicino è sempre più verde. La comunicazione fra committenti e progettisti di siti internet. Milano: Franco Angeli.

Cantoni, L. \& Tardini, S. (forthcoming). Internet (Routledge Introductions to Communications and Media Series). London: Routledge. 
CEC (2001) Communication from the Commission to the Council and the European Parliament, The eLearning Action Plan: Designing Tomorrow's Education. Brussels: COM 172 (28.3.2001).

CISCO (2001). Reusable Learning Object Strategy: Designing Information and Learning Objects through Concept, Fact, Procedure, Process and Principles Templates. Version 4.0. Cisco Systems, Inc.: Internet Learning Solutions Group.

Collis, B. \& Strijker, A. (2003). Re-Usable Learning Objects in Context. International Journal on E-Learning, Oct.-Dec., 5-16.

Curran, Ch.A. (1976). Counseling-Learning in Second Languages. East Dubuque, Ill.: Counseling Learning Publications.

Dahl, O.J. \& Nygaard, K. (1966). SIMULA - An Algol-Based Simulation Language, Communications of the ACM, 9, (9), 671-678.

Domenici, G. (1989). Manuale dell'orientamento e della didattica modulare. Bari: Laterza.

Dufeu, B. (1994). Teaching Myself. Oxford: O.U.P.

ECDL (2005). European Computer Driving Licence. Online: [www.ecdl.com].

EEC (n.d.). Learning Technology Glossary. Loughborough: University, Engineering Education Center. Online: [http://eec.lboro.ac.uk/learningtech/jtor.htm].

Gibbons, A.S., Nelson, J. \& Richards, R. (2000). The Nature and Origin of Instructional Objects. In D.A. Wiley (Ed.), Connecting Learning Objects to Instructional Design Theory: A Definition, a Metaphor and a Taxonomy.

Online: [http://reusability.org/read/chapters/gibbons.doc].

IMS (2005). Instructional Management Systems Project. Online: [www.imsproject.org].

Jonassen, D. \& Churchill, D. (2004). Is There a Learning Orientation in Learning Objects? International Journal on E-Learning, Apr.-Jun., 32-41.

LOM (2005). LOM Draft Standard. Online: [http://ltsc.ieee.org/wg12/materials.html].

LORNET (n.d.) LORNET Project Web Site. Online: [http://www.lornet.org].

LTSC (2000). IEEE Standards Board: Project Authorization Request. In D.A Wiley (Ed.), Connecting Learning Objects to Instructional Design Theory: A Definition, a Metaphor and a Taxonomy. Online: [http://reusability.org/read/chapters/wiley.doc].

LTSC (2005). Learning Technology Standards Committee. Online: [http://ltsc.ieee.org].

MAGF (2005). Master Professionalizzante in Gestione della Formazione. Online: [www.magf.unisi.ch].

Masie Center (2003). Making Sense of Learning Specifications \& Standards: A Decision Maker's Guide to their Adoption (Industry report, 2nd edition).

Online: [http://www.masie.com/standards/s3_2nd_edition.pdf].

MERLOT (2005). Multimedia Educational Resource for Learning and Online Teaching. Online: [www.merlot.org].

MET (2005). Master in Communication, Major in Education and Training. Online: [www.met.unisi.ch].

Parrish, P.E. (2004). The Trouble with Learning Objects. Educational Technologies Research and Development, 52, (1), 49-67.

Schulmeister, R. (2003). Taxonomy of Multimedia Component Interactivity: a Contribution to the Current Metadata Debate. Studies in Communication Sciences. Special Issue «New Media in Education» 61-80). Lugano.

SWISSLING (2005). SWISSLING. Online: [www.swissling.ch].

Wenger, E. (1998). Communities of Practice: Learning, Meaning and Identity. New York: Cambridge University Press.

Wiley, D.A. (Ed.) (2000a). Connecting Learning Objects to Instructional Design Theory: A Definition, a Metaphor and a Taxonomy. Online:[http://reusability.org/read/chapters/].

Wiley, D.A. (2000b). Connecting Learning Objects to Instructional Design Theory: A Definition, a Metaphor and a Taxonomy. In D.A Wiley (Ed.), Connecting Learning Objects to Instructional Design Theory: A Definition, a Metaphor and a Taxonomy. Online: [http://reusability.org/read/chapters/wiley.doc]. 
Key words: eLearning, laerning objects, online learning, information technologies

\section{eLearning und Ausbildung: der Fall von learning Objects}

\section{Zusammenfassung}

Modularität ist ein viel beachtetes und diskutiertes Thema im eLearning Bereich. Zum einen motiviert durchneue Technologien, die eine wichtige Unterstützung in der Entwicklung und Implementierung von modularen Programmen darstellen; zum andern angeregt durch die Entwicklung adäquater technischer wie auch pädagogischer Learning Objects.. Davon ausgehend haben verschiedene Autoren ein neues Object-orientiertes Lernparadigma vorgeschlagen, das auf der Differenzierung von identifizierbaren und reduzierbaren Erfahrungsbereichen innerhalb von Ausbildungsprozessen basiert. Obschon eine strukturelle und begriffliche Analogie mit der Software-Programmierung interessant und anregend ist, bleiben dennoch die starken Unterschiede zu beachten. Vor diesem Hintergrund diskutiert der Beitrag einerseitsErfahrungen, die an der USI und am ISPFP gemacht wurden, andererseits das Thema Learning Objects.

Schlagworte: eLearning, learning objects, online learning, Informationstechnologie

\section{eLearning et éducation modulaire: le cas du learning objects}

\section{Résumé}

Le thème de la modularité est un thème très vif dans le champ de l'eLearning, soit en ce qui concerne l'aide que les nouvelles technologies peuvent offrir pour la réalisation des parcours modulaires, soit en ce qui concerne la réalisation des objets learning techniquement et pédagogiquement adéquats. Plusieurs fois, on a proposé de parler de objet oriented learning, caractérisé par la possibilité de subdiviser l'expérience d'apprentissage en unités d'utilisation/expérience clairement identifiées et de dimensions réduites (ou minimales). Si l'analogie par rapport au monde de la programmation est suggestive et stimulante, il convient d'observer aussi la profonde différence qu'on rencontre. L'article présente soit le premier parcours, en se rapportant en particulier aux expériences conçues auprès de l'USI et auprès de l'ISPFP, soit le dernier, en offrant une panoramique des objets learning, et discutant quelques problématiques connexes.

Mots clés: elearning, learning objects, online learning, technologie de l'information 


\section{eLearning e modularità, il caso dei learning objects}

Riassunto

Il tema della modularità è un tema vivace nel campo dell'eLearning, sia per quanto riguarda l'aiuto che le nuove tecnologie possono offrire alla realizzazione di percorsi modulari, sia per quanto riguarda la realizzazione di learning objects tecnicamente e pedagogicamente adeguati. Da più parti, si è proposto di parlare di object oriented learning, la cui cifra ultima sarebbe proprio la possibilità di suddividere l'esperienza d'apprendimento in unità di fruizione/esperienza chiaramente identificate e di dimensioni ridotte (o minime). Se l'analogia rispetto al mondo della programmazione è suggestiva e stimolante, conviene osservare anche la profonda differenza che s'incontra. L'articolo presenta sia il primo percorso, dalla modularità all'eLearning, riferendo in particolar modo le esperienze realizzate all'USI e all'ISPFP, sia il secondo, dall'elearning alla modularità, offrendo una panoramica sui learning objects, e discutendo alcune problematiche connesse.

Parole chiave: eLearning, learning objects, online learning, tecnologie dell'informazione 
T h e m a 